\title{
Effects of long-term administration of a cocoa polyphenolic extract (Acticoa powder) on cognitive performances in aged rats
}

\author{
Jean-François Bisson ${ }^{1}$, Amine Nejdi ${ }^{1}$, Pascale Rozan ${ }^{1}$, Sophie Hidalgo ${ }^{1}$, Robert Lalonde ${ }^{2}$ \\ and Michaël Messaoudi ${ }^{1 *}$ \\ ${ }^{1}$ ETAP-Applied Ethology, 13 rue du Bois de la Champelle, Vandoeuvre-lès-Nancy 54500, France \\ ${ }^{2}$ CHUM/St-Luc, Neuroscience Research Center, 1058 St-Denis Street, Montréal H2X 3J4, PQ, Canada \\ (Received 29 May 2007 - Revised 13 September 2007 - Accepted 2 November 2007 - First published online 8 January 2008)
}

Numerous studies have indicated that increased vulnerability to oxidative stress may be the main factor involved in functional declines during normal and pathological ageing, and that antioxidant agents, such as polyphenols, may improve or prevent these deficits. We examined whether 1-year administration of a cocoa polyphenolic extract (Acticoa powder), orally delivered at the dose of $24 \mathrm{mg} / \mathrm{kg}$ per d between 15 and $27 \mathrm{months}$ of age, affects the onset of age-related cognitive deficits, urinary free dopamine levels and lifespan in old Wistar-Unilever rats. Acticoa powder improved cognitive performances in light extinction and water maze paradigms, increased lifespan and preserved high urinary free dopamine levels. These results suggest that Acticoa powder may be beneficial in retarding age-related brain impairments, including cognitive deficits in normal ageing and perhaps neurodegenerative diseases. Further studies are required to elucidate the mechanisms of cocoa polyphenols in neuroprotection and to explore their effects in man.

Cocoa polyphenols: Cognitive performances: Ageing: Lifespan: Rats

Because of their post-mitotic nature, neurons contend with cellular damage accumulated over many decades. The brain is more vulnerable to oxidative stress than other organs due to its low antioxidant protection system and increased exposure of target molecules to reactive oxygen species, one of the major damaging agents involved in age-associated decline ${ }^{(1)}$. Increased reactive oxygen species levels produced by mitochondrial activity, inflammatory processes and excessive glutamate accelerate neurodegenerative processes ${ }^{(2)}$. Some parameters related to neurotransmission also decline during normal ageing ${ }^{(3-5)}$.

Numerous epidemiological studies indicate that dietary flavonoids derived from fruits, vegetables, red wine and green tea decrease the risk of death from $\mathrm{CHD}^{(6,7)}$, cancer $^{(8)}$ and stroke ${ }^{(9)}$, and may prevent neurodegenerative diseases and diabetes mellitus ${ }^{(10)}$. Only recently have the beneficial effects of dietary polyphenols come to the attention of nutritionists $^{(11)}$. Polyphenols are present in plants in the form of non-conjugated molecules, including $(-)$-epicatechin and $(+)$-catechin, as well as their oligomers, also named procyanidins ${ }^{(12-14)}$. Cocoa-derived products contain high levels of flavonoids ${ }^{(12,15,16)}$ and show potent antioxidant effects ${ }^{(17)}$. Biomarkers associated with CVD, such as oxidant defence molecules, LDL oxidation state and platelet function, have been assessed after acute consumption of chocolate and $\operatorname{cocoa}^{(18-20)}$. The increase in blood epicatechin after acute procyanidin-rich chocolate consumption was associated with increased plasma antioxidant capacity and decreased plasma 2-thiobarbituric acid reactive substances ${ }^{(20)}$. In addition, (+)catechin and $(-)$-epicatechin delayed lipid oxidation as well as depleted $\alpha$-tocopherol and $\beta$-carotene levels induced by a free radical generator in human oxidized plasma ${ }^{(21)}$. It was shown that consumption of green tea prevented LDL oxidation in $\operatorname{man}^{(22)}$ and that tea catechins attenuated the development of atherosclerosis in apoE-deficient mice ${ }^{(23)}$. The antioxidant properties of polyphenols and their beneficial effects on cognition have been demonstrated in animal studies ${ }^{(24)}$. There is a possible role for $(-)$-epicatechin in reducing neurodegenerative disorders such as Parkinson's and Alzheimer's diseases ${ }^{(25,26)}$. Polyphenols may also possess other types of neuroprotective effects ${ }^{(27,28)}$.

The main purpose of the present study was to investigate the effects of Acticoa powder, a cocoa polyphenolic extract, on cognitive function and lifespan in aged Wistar-Unilever rats, assessed with light extinction ${ }^{(29-31)}$ and water maze tests, the latter adapted from Morris ${ }^{(32)}$ in which rats were let go from the same starting position. The rats were also evaluated for urinary free dopamine levels, susceptible to agerelated decreases in Wistar rats ${ }^{(33)}$.

\section{Materials and methods}

Animals

Eighteen male Wistar-Unilever rats (Harlan, The Netherlands), weighing $250-275 \mathrm{~g}$ at reception, were housed three 
per cage in $48 \times 27 \times 20 \mathrm{~cm}$ polycarbonate cages (U.A.R., Epinay-Sur-Orge, France) in a regulated environment (temperature $22 \pm 2^{\circ} \mathrm{C}$; humidity $50 \pm 10 \%$ ), provided standard food (food pellets M20; Dietex, Saint Gratien, France) and tap water ad libitum, and maintained on a $12 \mathrm{~h}$ light/dark cycle (lights on 20.00-08.00 hours).

After an 8-month acclimatization period in our facility, the rats were matched according to weight and randomly assigned to one of two groups $(n 9)$ : control-vehicle or Acticoa powder (cocoa polyphenolic extract) at the dose of $24 \mathrm{mg} / \mathrm{kg}$ per d (AP24), given by oral gavage. The rats were tested for cognitive functions at 9,13 and 15 months, received AP24 or its vehicle (spring water), and were then retested at 17, 21 and 25 months for light extinction and water maze tests.

The rats used in the present study were treated according to rules provided by the ASAB Ethical Committee (1993) and the Canadian Council on Animal Care (1993). All standard operating procedures were in compliance with the European Communities Council Directive 86/609/EEC of 24 November 1986 on the approximation of laws, regulations and administrative provisions of the Member States regarding the protection of animals used for scientific purposes (Official Journal L 358, 18 December 1986, pp. 0001-0028).

\section{Tested product}

The solvent-free Acticoa powder was provided by Barry Callebaut France (Louviers, France). It was isolated from nonroasted beans using the patented Acticoa process recently developed by Barry Callebaut France. The general composition of AP24 was as follows $(\mathrm{g} / 100 \mathrm{~g}): 3.5 \mathrm{~g}$ moisture, $29.4 \mathrm{~g}$ proteins, $13.2 \mathrm{~g}$ fat, $12.8 \mathrm{~g}$ carbohydrates, $3.8 \mathrm{~g}$ fibres, $2.4 \mathrm{~g}$ minerals and $34.9 \mathrm{~g}$ total polyphenols. The percentages related to the polyphenols in AP24 determined by HPLC were $88.5 \%$ procyanidins including $0.21 \%$ anthocyanins, $10 \%$ epicatechin, $1 \%$ epicatechin gallate and $0.5 \%$ catechin. The product was freshly prepared every day; it was dissolved in spring water and administered at a dose of $24 \mathrm{mg} / 5 \mathrm{ml}$ per $\mathrm{kg}$ body weight. AP24 and vehicle were orally administered for 12 months from the age of 15-27 months. After daily administration, the rats were allowed free access to standard food pellets and were weighed three times per week.

Only a single dosage of AP24 was investigated on the basis of results from a chronic experiment which showed its beneficial effects on prostate cancer prevention in rats ${ }^{(34)}$.

\section{Procedures}

Weight change and food and water consumption. The body weight of each rat was recorded three times per week during the whole experimental period. Food and water consumption were recorded every week from Monday to Friday, for each cage, in order to estimate the quantity of food and water ingested by rats. Then the mean quantities of food and water were calculated in $\mathrm{g} / 100 \mathrm{~g}$ body weight for rats of each cage in the two groups.

Cognitive testing. All cognitive tests were recorded by experimenters unaware of administered treatments.

Light extinction: light extinction was tested before treatment at 9, 13 and 15 months of age and after treatment at 17, 21 and 25 months of age. Learning performance was assessed by means of an operant conditioning test based on the natural aversion of rats to bright light ${ }^{(29-31)}$. The rat was placed in a strongly illuminated (1200 lux) cage $(50 \times 40 \times 37 \mathrm{~cm})$ equipped with two levers. By pressing the active lever the rat switched off the light allowing access to a $30 \mathrm{~s}$ period of darkness, whereas the inactive lever had no effect on the environment. The test lasted $20 \mathrm{~min}$ and the number of active and inactive lever presses were recorded.

Water maze: at 8,12 and 15 months of age, the rats were trained to find a hidden platform $(1 \mathrm{~cm}$ beneath water surface at $\left.23^{\circ} \mathrm{C}\right)$ in a tank $(150 \mathrm{~cm}$ diameter $)$ filled with water from the same starting position for five trials per test session with a maximal duration of $180 \mathrm{~s}$ for each trial. The platform was placed away from the wall in a constant quadrant position during the trials. On each trial, the rats were allowed to stay on the platform for $30 \mathrm{~s}$ and then were immediately placed back in the water for the next trial. When unable to find the platform, the rats were placed on it for the same amount of time. At 17, 21 and 25 months of age, the rats were retested under treatment or placebo with the same procedure. In our simplified procedure, the rat is proficient in learning to locate more quickly the hidden platform by memorizing its position during a single five-trial session.

Urinary dopamine levels. Rats were individually placed in metabolic cages for $7 \mathrm{~h}$ from 09.00 to 16.00 hours for the collection of urine samples. Urinary dopamine levels were assayed at 12, 15, 18, 21, 24 and 27 months of age by HPLC with electrochemical detection. Aliquots of $1.0 \mathrm{ml}$ acidified urine were placed in $5 \mathrm{ml}$ conical-base glass vials with $50 \mathrm{mg}$ alumina, and the samples were adjusted to $\mathrm{pH} 8.6$ by adding Tris buffer. The adsorbed dopamine was then eluted from the alumina with $200 \mu \mathrm{l}$ of $0 \cdot 2 \mathrm{~mol} / \mathrm{HClO}_{4}$ on Costar Spin-X microfilters. In the final phase, $50 \mu l$ of the eluate were injected into an HPLC apparatus (Gilson Medical Electronics, Villiers-le-Bel, France) with a minimal limit of detection of $4 \mu \mathrm{g} / \mathrm{l}$.

\section{Lifespan}

Throughout the experiment, the date of death of each rat was noted in order to determine the mean lifespan in each group.

\section{Statistical analysis}

Due to the relatively small number of rats per group, which decreased during the course of the study, and due to unequal variances, non-parametric tests ${ }^{(35)}$ were used. The MannWhitney $U$ test was used to compare cognitive performances of the two groups. For each group, the Friedman test was employed to compare the repeated cognitive performances throughout the test sessions; whenever significant, the Wilcoxon test was used to compare the performances of two consecutive water maze tests and to evaluate lever discrimination in the light extinction test by comparing the numbers of active and inactive lever presses. Survival data were analysed using the Kaplan-Meier method ${ }^{(36)}$. The difference between survival in the two groups was tested using the log rank test. All statistical analyses were carried out with StatView ${ }^{\circledR} 5$ software (SAS Inc., Cary, NC, USA). The results are expressed as means and their standard errors. Differences were considered to be significant at $P<0 \cdot 05$. 


\section{Results}

Weight change and food and water consumption

No significant differences were observed between the body weight and food and water consumption of the two groups recorded throughout the study period (data not shown).

\section{Cognitive testing}

Light extinction. Total lever presses: as shown in Fig. 1, no significant group differences were apparent for total number of lever presses prior to Acticoa powder or vehicle administration at 9, 13 and 15 months of age (Mann-Whitney $U$ test: $U$ 29.50, NS; $U 24 \cdot 00, \mathrm{NS} ; U 31.50$, NS, respectively). But at 17, 21 and 25 months of age, total lever pressing activity was significantly more elevated in AP24-treated rats (Mann-Whitney $U$ test: $U$ 13.0, $P<0.03 ; U$ 4.50, $P<0.004$; $U 5 \cdot 00, P<0 \cdot 04$, respectively).

Lever discrimination: as shown in Fig. 2, control rats (treated with the vehicle) failed to show a significant discrimination between the two levers during baseline at 9, 13 and 15 months (Wilcoxon test: $z$ 0.95, NS; $z$ 1.27, NS; $z$ 0.68, NS, respectively) and during the treatment period at 17,21 and 25 months (Wilcoxon test: $z \quad 0.43$, NS; $z \quad 0.65$, NS; $z \quad 0 \cdot 38$, NS, respectively). Although AP24-treated rats did not discriminate between the two levers at baseline (Wilcoxon test: $z$ 0 34, NS; $z$ 0.57, NS; $z$ 1.02, NS, respectively), lever discrimination was observed at 17 and 21 months (Wilcoxon test: $z 2 \cdot 32, P<0 \cdot 02$; $z$ 2.68, $P<0.008$, respectively). But at 25 months, presses on the active lever only tended to be higher than those on the inactive one (Wilcoxon test: $z 1 \cdot 70, P<0 \cdot 09$ ).

Water maze. Global performances: during baseline at 8 , 12 and 15 , and during treatment at 17 months of age, no intergroup differences were found for escape latencies (MannWhitney $U$ test: $U$ 34.50, NS; $U$ 32.50, NS; $U$ 35, NS; $U 20 \cdot 5$, NS, respectively; Fig. 3). But at 21 and 25 months, escape latencies of AP24-treated rats were significantly

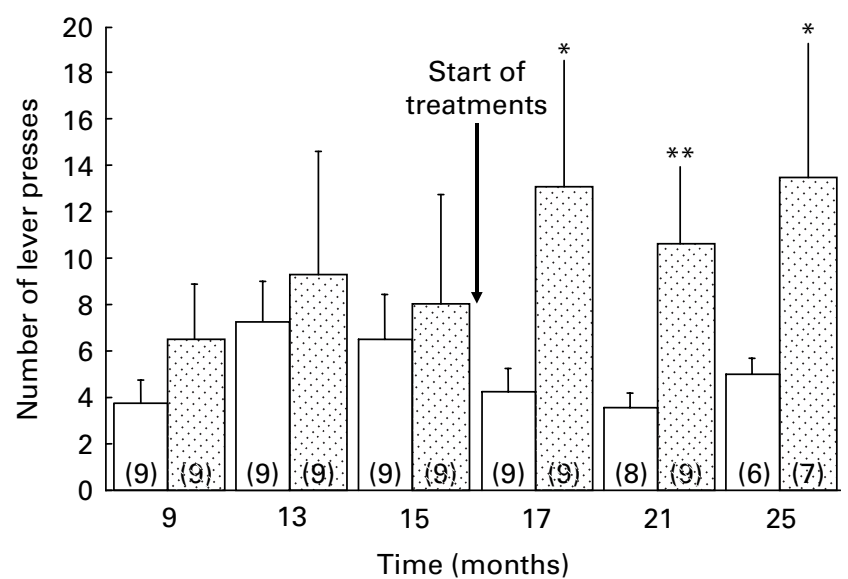

Fig. 1. Total number of lever presses (active + inactive lever presses) in the light extinction test before $(9,13$ and 15 months) and after the start of treatments (17, 21 and 25 months) in control rats $(\square)$ and in rats fed Acticoa powder $(24 \mathrm{mg} / \mathrm{kg}$ per d; AP24; $)$. The numbers in parentheses are the number of rats remaining in each group. Values are means with their standard errors depicted by vertical bars. Mean values were significantly different from those of the control group (Mann-Whitney $U$ test): ${ }^{\star} P<0.05$, ${ }^{\star \star} P<0.01$. lower than those of control rats (Mann-Whitney $U$ test: $U$ 6.00, $P=0.007$; $U$ 0.00, $P=0.006$, respectively).

Long-term memory: long-term memory was evaluated by comparing group performances over months using the Wilcoxon test (Fig. 3). Both groups improved their performances from month 8 to 12 ( $z, 2.67, P<0.008$ for AP24-treated rats; $z 2.52, P<0.02$ for controls) and from month 8 to 15 (z 2.67, $P<0.008$ for AP24-treated rats; $z$ 2.52, $P<0.02$ for controls). The performance of control rats was still stable from month 15 to $17(z 0 \cdot 154, \mathrm{NS})$, but significantly deteriorated at 21 and 25 months $(z 2 \cdot 37, P=0 \cdot 018 ; z 2 \cdot 02, P=0 \cdot 043$, respectively). In contrast, the performance of AP24-treated rats was stable from 15 to $17(z 0 \cdot 48, \mathrm{NS})$, from 15 to $21(z 0 \cdot 42$, NS) and from 15 to 25 ( $z 0 \cdot 31$, NS) months.

Short-term memory: short-term memory was assessed by comparing group performances over daily trials (Fig. 4). During the first water maze test at baseline, both groups improved their escape latencies from trial 1 to trial 5 (Friedman test: $\chi^{2}(4 \mathrm{df}) 20 \cdot 56, P=0.0004$ for AP24-treated rats; $\chi^{2}(4 \mathrm{df})$ $10 \cdot 58, P=0.03$ for controls). During 12- and 15-month test sessions (baseline), escape latencies of both groups remained low throughout every trial to the extent that short-term memory assessment became meaningless (month 12: $\chi^{2}(4 \mathrm{df}) 7 \cdot 17$, NS for AP24-treated rats; $\chi^{2}(4 \mathrm{df}) 10 \cdot 80, P=0.03$ for controls; month 15: $\chi^{2}(4 \mathrm{df}) 14.92, P=0.005$ for AP24-treated rats; $\chi^{2}(4 \mathrm{df}) 7.52$, NS for controls) (Figs. 4 (A), (B) and (C)).
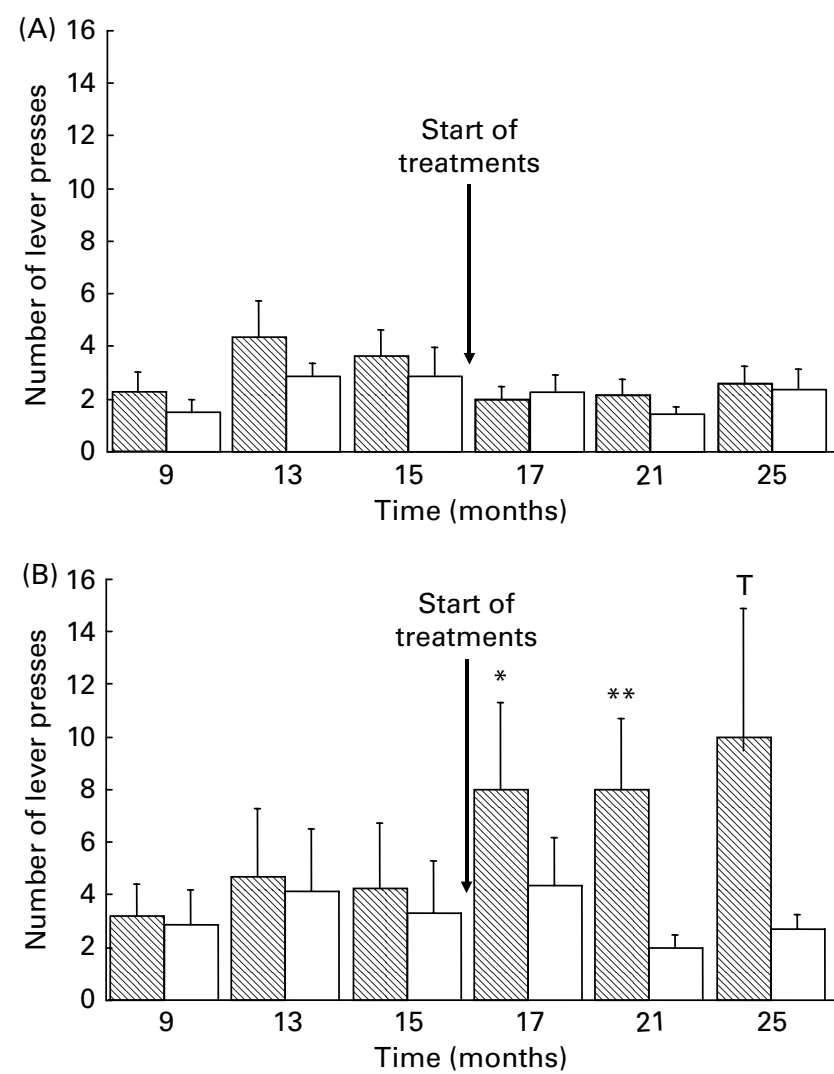

Fig. 2. Discrimination between active $(\varangle)$ and inactive $(\square)$ levers in the light extinction test before $(9,13$ and 15 months) and after the start of treatments (17, 21 and 25 months) in control rats $(A)$ and in rats fed Acticoa powder $(24 \mathrm{mg} / \mathrm{kg}$ per d; AP24; B). Values are means with their standard errors depicted by vertical bars. Mean values were significantly different from those of the inactive levers (Wilcoxon test): ${ }^{\top} P<0.10,{ }^{\star} P<0.05,{ }^{\star \star} P<0.01$. 


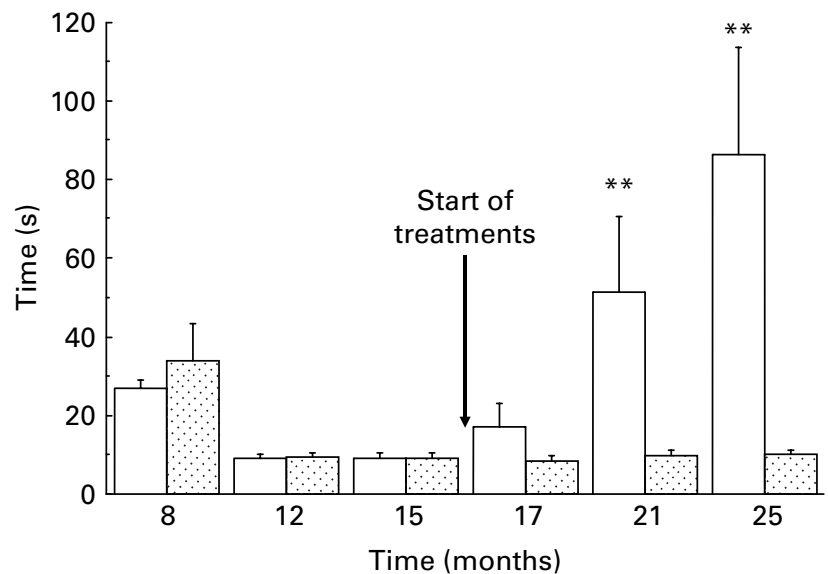

Fig. 3. Water maze performances before ( 8,12 and 15 months) and after the start of treatments $(17,21$ and 25 months) in control rats $(\square)$ and in rats fed Acticoa powder $(24 \mathrm{mg} / \mathrm{kg}$ per d; AP24; $\square)$. Results are given as mean latencies over five trials before finding the hidden platform in each test session. Values are means with their standard errors depicted by vertical bars. Mean values were significantly different from those of the AP24-treated rats (Mann-Whitney $U$ test): ${ }^{\star *} P<0.01$.
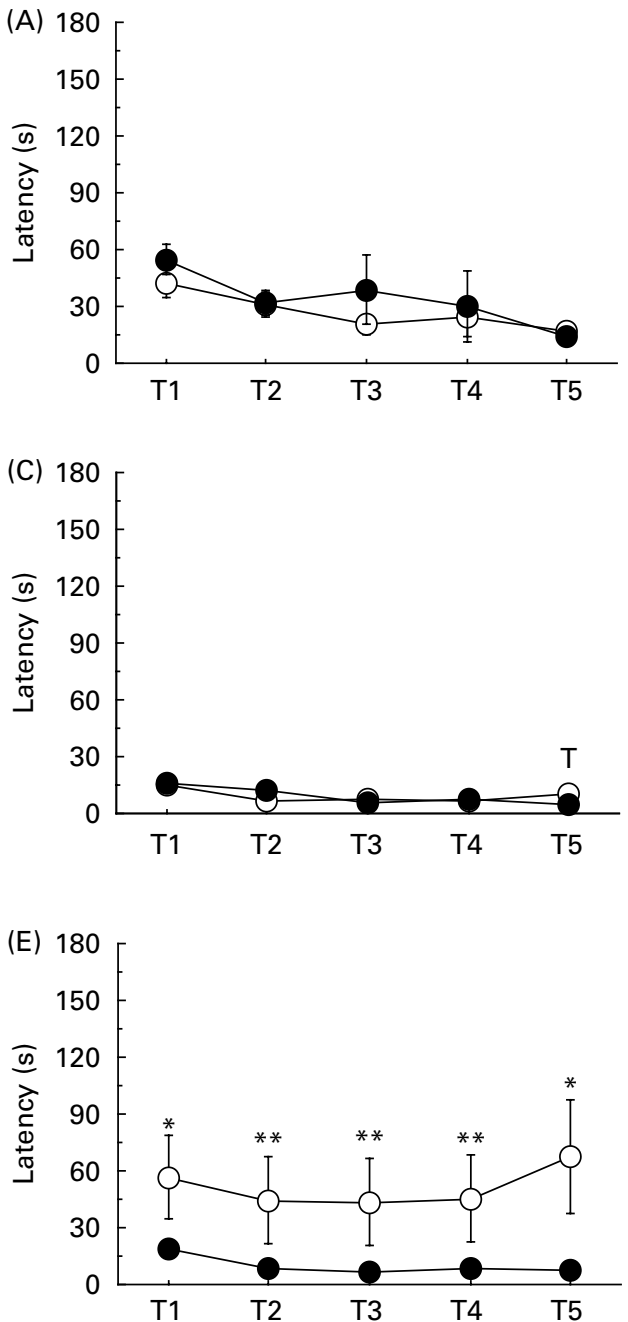

At the 17-month test session, AP24-treated and control rats improved their latency to find the platform from trial 1 to trial 2 ( $z$ 2.67, $P=0 \cdot 008 ; z 2 \cdot 37, P=0 \cdot 018$, respectively). Between trial 2 and trial 5, latencies remained low and stable in the two groups (Friedman test: $\chi^{2}(3 \mathrm{df}) 2 \cdot 87, \mathrm{NS} ; \chi^{2}(3 \mathrm{df}) 0 \cdot 79, \mathrm{NS}$, respectively). However, the performance of AP24-treated rats was better than that of controls for trials 2, 3 and 4 (Fig. 4 (D)). At the 21- and 25-month test sessions, AP24-treated rats improved their latencies on the first two trials (Wilcoxon test: $z 2 \cdot 08, P=0.04 ; z 2 \cdot 07, P=0.03$, respectively) and between trial 2 and trial 5 , their latencies remained low and stable (Friedman test: $\chi^{2}(3 \mathrm{df}) 4 \cdot 01, \mathrm{NS} ; \chi^{2}(3 \mathrm{df}) 2 \cdot 50, \mathrm{NS}$, respectively). In contrast, latencies of control rats showed no improvement between trial 1 and trial 5 (Friedman test: $\chi^{2}(4 \mathrm{df}) 2 \cdot 84$, NS; $\chi^{2}(4 \mathrm{df}) 2 \cdot 26$, NS, respectively). Over the five trials of these sessions, the performance of AP24-treated rats was significantly better than that of control rats (Figs. 4 (E) and (F)).

\section{Urinary free dopamine}

As seen in Fig. 5, urinary free dopamine concentrations remained stable in the two groups from 12 to 15 months of
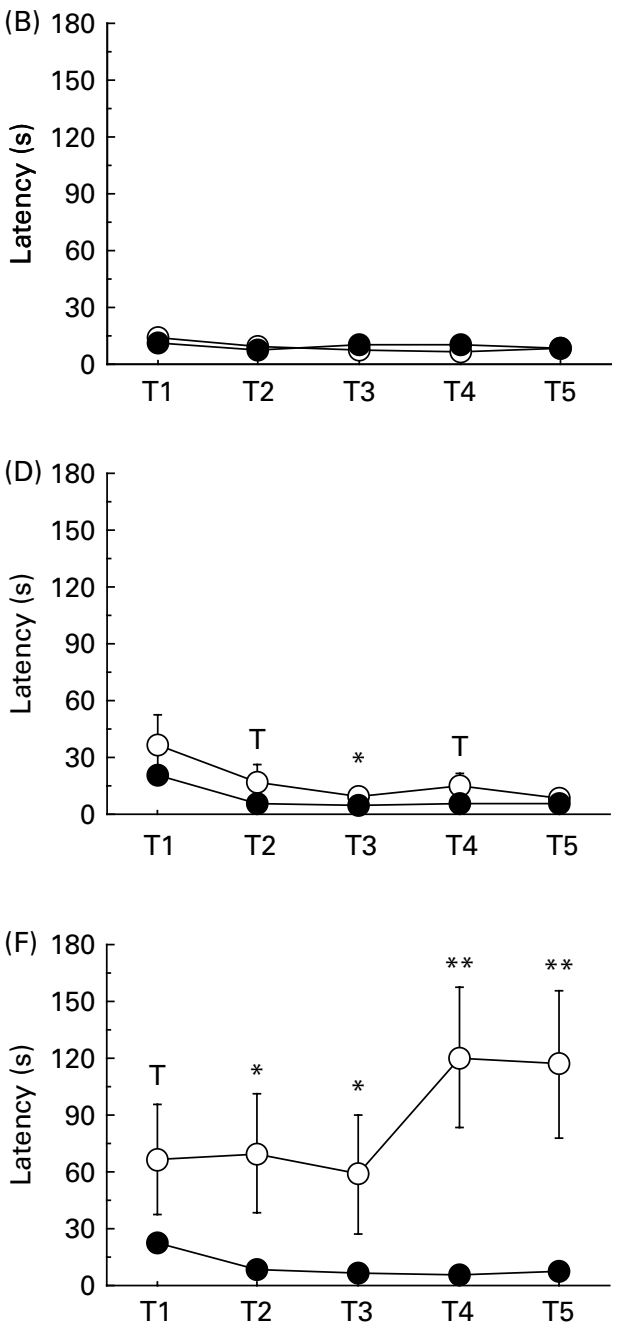

Fig. 4. Water maze performances at $8(A), 12(B), 15$ months (C) (before treatment), and $17(D), 21(E)$ and 25 (F) (period of treatment) months of age in control rats $(O)$ and in rats fed Acticoa powder $(24 \mathrm{mg} / \mathrm{kg}$ per d; AP24; $\bullet$ ). Results are given as mean latencies from the five trials of the test session (T1-T5). Mean values were significantly different from those of the AP24-treated rats (Mann-Whitney $U$ test): ${ }^{\top} P<0 \cdot 10,{ }^{\star} P<0 \cdot 05,{ }^{\star \star} P<0 \cdot 01$. 
age and no group difference was discerned (Mann-Whitney $U$ test: $U 10, \mathrm{NS} ; U 6$, NS, respectively). Urinary free dopamine concentrations of AP24-treated rats were significantly lower than those of control rats at 18 months of age $(U 2$, $P<0.02$ ), but significantly higher at 24 and 27 months of age (Mann-Whitney $U$ test: $U 0, P<0.002 ; U 0, P<0.008$, respectively). While dopamine levels remained stable in AP24-treated rats from 18 to 27 months (Friedman test: $\left.\chi^{2}(3 \mathrm{df}) 0 \cdot 80, \mathrm{NS}\right)$, values of control rats tended to decline (Friedman test: $\left.\chi^{2}(3 \mathrm{df}) 7 \cdot 46, P<0.06\right)$.

\section{Lifespan}

The log-rank statistical test showed a significant increase of survival times in the AP24-treated group in comparison to control rats $\left(\chi^{2}(1 \mathrm{df}) 5 \cdot 169, P=0 \cdot 025\right)$, corresponding to a longer lifespan of about $11 \%$ over the 27 -month period (Fig. 6).

\section{Discussion}

\section{Cognitive testing}

The main purpose of the present work was to determine whether a daily dose of Acticoa powder ingested by aged rats over a 12-month period retards the onset of age-related cognitive deficits. In the light extinction test, AP24-treated rats had more total lever pressing activity than control rats. Moreover, unlike placebo-treated controls, AP24-treated rats exhibited significant discrimination between active and inactive levers at 17 and 21 months of age. The reason why control rats failed to discriminate is uncertain. We previously observed significant lever discrimination in 3-month-old male Wistar rats ${ }^{(29-31)}$. We suspect that age level is critical and it should be interesting to evaluate younger Wistar-Unilever rats in the same paradigm. It remains to be determined whether the elevated lever activity of AP24-treated rats is generalizable to exploratory activity in the open-field and holeboard, susceptible to decline as a result of advanced ageing in rats and mice ${ }^{(37)}$. It also remains to be determined why

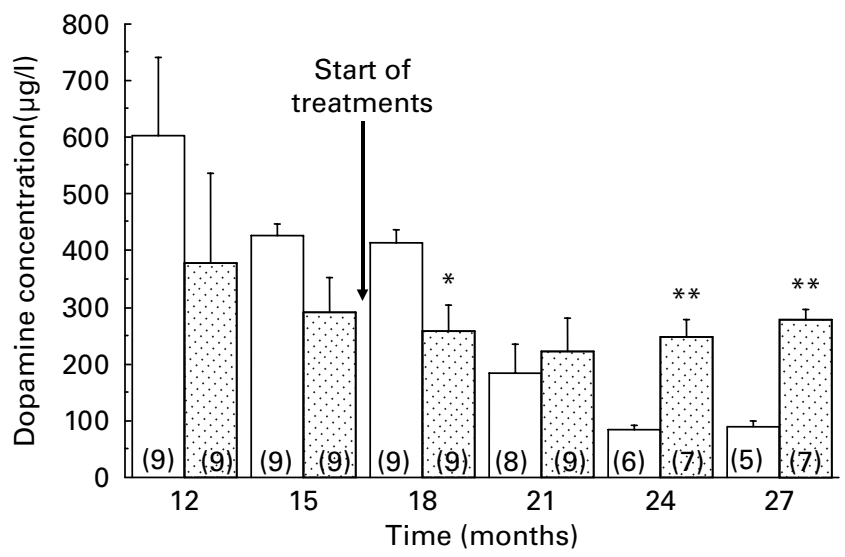

Fig. 5. Urinary free dopamine concentrations before (12 and 15 months) and after the start of treatments $(18,21,24$ and 27 months) in control rats ( $\square$ ) and in rats fed Acticoa powder $(24 \mathrm{mg} / \mathrm{kg}$ per d; AP24; $\mathrm{q})$. The numbers in parentheses are the number of rats remaining in each group. Values are means with their standard errors depicted by vertical bars. Mean values were significantly different from those of the control group (Mann-Whitney $U$ test): ${ }^{\star} P<0.05,{ }^{\star \star} P<0.01$.

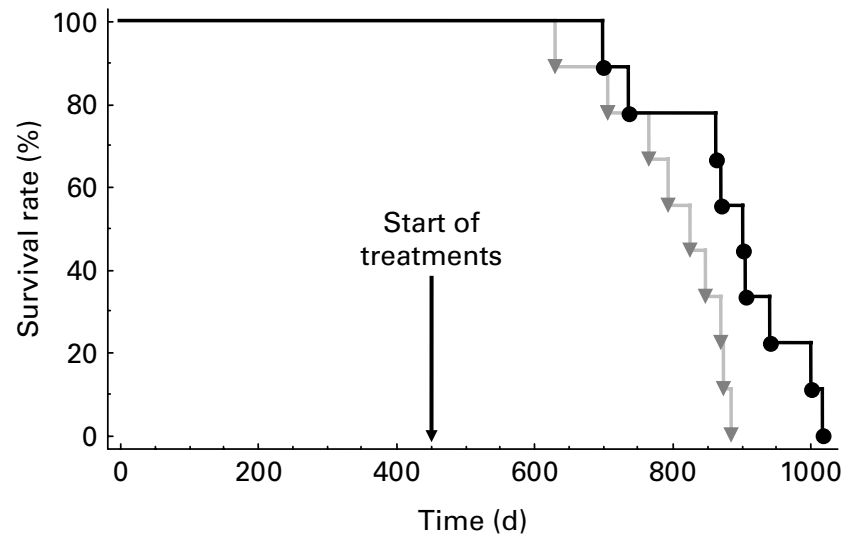

Fig. 6. Survival rates of control rats $(\nabla)$ and rats fed Acticoa powder $(24 \mathrm{mg} / \mathrm{kg}$ per d; AP24; $)$. Survival times of rats were analysed using the Kaplan-Meier method and the log-rank test.

the AP24 group discriminates. One possiblity is faciliation of cognitive processes. A second possibility is that light is more aversive to them. There is a need to assess the effects of this substance on photophobia and other anxiety tests.

While water maze performance declined in control rats at 21 and 25 months of age, it remained stable in AP24-treated rats. At 21 and 25 months, but not at 17 months, escape latencies of AP24-treated rats were lower than those of control rats. Both long- and short-term memory processes were improved by the cocoa polyphenolic extract, as evaluated by month-to-month or trial-to-trial performances. The present results demonstrate beneficial effects of Acticoa powder on spatial learning.

Many studies indicate that age-associated neurobehavioural deficits are attenuated by dietary supplementation with potent antioxidant activity, such as Ginkgo biloba flavonoids, including memory ${ }^{(38)}$, attention ${ }^{(39)}$ and calcium-induced increases in oxidative metabolism $^{(40)}$. It may be possible to reduce the deleterious effects of Alzheimer's disease with such supplements $^{(41)}$ or at least delay the physiological impairment associated with normal ageing ${ }^{(42)}$. In particular, Moriguchi et al. ${ }^{(43)}$ reported that a garlic extract prevented brain atrophy, as well as learning and memory impairments in the senescence accelerated mouse ${ }^{(44)}$.

The present results are in accordance with those of Joseph et al. (24) concerning the beneficial action of dietary supplementation with spinach, strawberry and blueberry extracts high in flavonoid levels as well as antioxidant activity ${ }^{(45)}$ on neuronal and cognitive functions in aged rats. Moreover, age-related declines in spatial memory tasks and hippocampal plasticity parameters were improved by antioxidant-rich diets containing blueberries ${ }^{(46,47)}$. Likewise, tea polyphenols immediately after ischaemia improved memory impairment and reduced hippocampal damage in mice ${ }^{(48)}$ and in gerbils $^{(49)}$. In the mouse hippocampal model system for oxidative stress, many flavonoids protected HT-22 cells from glutamateinduced toxicity as well as other oxidative insults ${ }^{(50)}$.

\section{Urinary free dopamine}

Dopamine is an essential neurotransmitter enabling smooth, controlled movements as well as efficient memory, attention 
and problem-solving function. Three months after the start of the treatment period, urinary free dopamine levels were paradoxically much higher in control than AP24-treated rats. At 21 months of age (6 months of treatment), no significant difference was observed between the dopamine levels of the two groups. At 24 and 27 months of age, urinary dopamine concentration declined in control rats, but remained relatively high and stable in AP24-treated rats. On the basis of the present results, the variability of urinary dopamine is probably not due to the salt content in the extract. Urinary dopamine levels exhibited by control rats are concordant with the agerelated decrease found in Wistar rats ${ }^{(33)}$. Some studies directly associate the level of free dopamine in urine with the severity of the Parkinsonian syndrome ${ }^{(51,52)}$. Hoehn et al. ${ }^{(52)}$ concluded that, although many peripheral sources contribute to urinary free dopamine, a small decrease in the level may actually reflect the severity of the disturbance of central dopamine metabolism and the known deficiency of dopamine in the neurons of the Parkinsonian brain. Green tea polyphenols inhibited the uptake of $\left[{ }^{3} \mathrm{H}\right]$ dopamine and 1-methyl-4-phenylpyridinium by dopamine transporters and partially protected embryonic rat mesencephalic dopaminergic neurons from 1-methyl-4-phenylpyridinium-induced injury ${ }^{(53)}$. Similarly, potent neuroprotective properties of green tea polyphenols were demonstrated with respect to striatal dopamine depletion and substantia nigra dopaminergic neuronal loss caused by 1-methyl4-phenyl-1,2,5,6-tetrahydropyridine in mice ${ }^{(54)}$. Reactive oxygen species are involved in the decline of functions associated with ageing ${ }^{(1)}$ and flavonoid administration attenuated apoptotic injury of mesencephalic dopamine neurons caused by oxidative stress ${ }^{(55)}$. Joseph et al. ${ }^{(24)}$ examined the brain tissues of blueberry-supplemented rats and found that dopamine levels were significantly higher than those of control rats.

Despite distinct chemical structures, cocoa antioxidant effects are similar to those of tea or blueberry, providing antioxidant defences against reactive oxygen species ${ }^{(12,56)}$. Cocoa polyphenol extracts may therefore protect vulnerable structures such as the nigro-striatal system against dopamine depletion in psychopathological and neurological disorders $^{(57-61)}$.

\section{Lifespan}

The lifespan of AP24-treated rats was prolonged relative to placebo by approximately $11 \%$ over the 27-month test period. The mechanisms underlying prolongation of the lifespan of the Acticoa powder remain to be fully established. It was demonstrated that cocoa powder enhances the level of antioxidative activity in rat plasma ${ }^{(62,63)}$ and among human subjects, a flavonoid-rich chocolate increased plasma antioxidant capacity and reduced the amounts of plasma 2-thiobarbituric acid-reactive substances ${ }^{(64)}$. Lee et al. ${ }^{(65)}$ showed that cocoa powder and cocoa extracts exhibit greater antioxidant capacity than many other flavanol-rich foods and food extracts, such as green and black tea, and red wine.

However, the beneficial effects of the cocoa extract are attributable not only to antioxidant properties of its polyphenol constituents (procyanidins and methylxanthines), but also via inhibition of nitric oxide-stimulated protein kinase $\mathrm{C}$ activity, since flavanols improved nitric oxide-dependent vasodilatation even in the presence of pre-existing endothelial dysfunction ${ }^{(66,67)}$. Cocoa polyphenols may improve vasodilatation, dependent on epicatechin ${ }^{(68)}$. The cocoa polyphenolic extract may also act on the cardiovascular system through a variety of mechanisms including reduced LDL oxidation ${ }^{(19,62,69,70)}$, improved endothelium-dependent relaxation ${ }^{(71)}$, modulation of cytokines and eicosanoids involved in the inflammatory response $^{(72-74)}$, and inhibition of platelet activation ${ }^{(20,75,76)}$.

\section{Conclusion}

Since AP24 administration did not show any influence on weight and on food and water consumption of treated rats throughout the experimental period, the benefits observed with the AP24 cocoa extract are not due to dietary restriction. The present results suggest that Acticoa powder may be beneficial in retarding age-related brain impairments, including cognitive deficits in normal ageing and perhaps neurodegenerative diseases. On the basis of the present results, it is of interest to carry out further in-depth preclinical and clinical studies on the neurobehavioural actions of Acticoa powder in order to determine whether age-related dysfunctions may be prevented and to elucidate the mechanisms of cocoa polyphenols in neuroprotection.

\section{Acknowledgements}

We are grateful to the Barry Callebaut Group (France) for supplying Acticoa powder samples. J.-F. B., M. M. and S. H. were responsible for performing the study. M. M., A. N. and P. R. were responsible for data management and statistical expertise. J.-F. B., M. M., A. N. and P. R. were also responsible for data interpretation and manuscript writing. R. L. contributed to data interpretation and manuscript writing. There were no conflicts of interest.

\section{References}

1. Biesalski HK (2000) The role of antioxidants in nutritional support. Nutrition 16, 593-596.

2. Huber A, Stuchbury G, Burkle A, Burnell J \& Munch G (2006) Neuroprotective therapies for Alzheimer's disease. Curr Pharm Des 12, 705-717.

3. Egashira T, Takayama F \& Yamanaka Y (1996) Effects of bifemelane on muscarinic receptors and choline acetyltransferase in the brains of aged rats following chronic cerebral hypoperfusion induced by permanent occlusion of bilateral carotid arteries. Jpn J Pharmacol 72, 57-65.

4. Gould TJ \& Bickford P (1997) Age-related deficits in the cerebellar b-adrenergic signal transduction cascade in Fischer 344 rats. J Pharmacol Exp Ther 281, 965-971.

5. Levine MS \& Cepeda C (1998) Dopamine modulation of responses mediated by excitatory amino acids in the neostriatum. Adv Pharmacol 42, 724-729.

6. Hertog MG, Feskens EJM, Hollman PC, Martijn MB \& Kromhout D (1993) Dietary antioxidant flavonoids and risk of coronary heart disease: The Zutphen Elderly Study. Lancet 342, 1007-1011.

7. Hertog MG, Kromhout D, Aravanis C, et al. (1995) Flavonoid intake and long-term risk of coronary heart disease and cancer in the Seven Countries Studies. Arch Intern Med 155, 381-386.

8. Steinmetz KA \& Potter JD (1991) Vegetables, fruit and cancer. 1. Epidemiology. Cancer Causes Control 2, 325-357. 
9. Keli SO, Hertog MG, Feskens EJ \& Kromhout D (1996) Dietary flavonoids, antioxidant vitamins, and incidence of stroke: the Zutphen study. Arch Intern Med 156, 637-642.

10. Scalbert A, Johnson I \& Saltmarsh M (2005) Polyphenols: antioxidant and beyond. Am J Clin Nutr 81, Suppl. 1, 215S-217S.

11. Sies H \& Stahl W (1995) Vitamins E and C, beta-carotene, and other carotenoids as antioxidants. Am J Clin Nutr 62, Suppl. 1, 1315S-1321S.

12. Adamson GE, Lazarus SA, Mitchel AE, et al. (1999) HPLC method for the quantification of procyanidins in cocoa and chocolate samples and correlation to total antioxidant capacity. J Agric Food Chem 47, 773-781.

13. Lazarus SA, Hammerstone JF \& Schmitz HH (1999) Chocolate contains additional flavanoids not found in tea. Lancet 354, 1825.

14. Natsume M, Osakabe N, Yamagishi M, Takizawa T, Nakamura T, Miyatake H, Hanato T \& Yoshida T (2000) Analyses of polyphenols in cacao liquor, cocoa, and chocolate by normal phase HPLC. Biosci Biotechnol Biochem 64, 2581-2587.

15. Hammerstone JF, Lazarus SA, Mitchell AE, Rucker R \& Schmitz HH (1999) Identification of procyanidins in cocoa (Theobroma cacao) and chocolate using high-performance liquid chromatography/mass spectrometry. J Agric Food Chem 47, 490-496.

16. Hammerstone JF, Lazarus SA \& Schmitz HH (2000) Procyanidin content and variation in some commonly consumed foods. J Nutr 130, Suppl. 85, 2086S-2092S.

17. Arteel GE \& Sies H (1999) Protection against peroxynitrite in cocoa polyphenols oligomers. FEBS Lett 462, 167-170.

18. Holt RR, Lazarus SA, Sullards MC, Zhu QY, Schramm DD, Hammerstone JF, Fraga CG, Schmitz HH \& Keen CL (2002) Procyanidin dimer B2 [epicatechin-(4beta-8)-epicatechin] in human plasma after the consumption of a flavanol-rich cocoa. Am J Clin Nutr 76, 798-804.

19. Kondo K, Hirano R, Matsumoto A, Igarashi O \& Itakura $\mathrm{H}$ (1996) Inhibition of LDL oxidation by cocoa. Lancet 348, 1514.

20. Rein D, Paglieroni TG, Wun T, Pearson DA, Schmitz HH, Gosselin R \& Keen CL (2000) Cocoa inhibits platelet activation and function. Am J Clin Nutr 72, 30-35.

21. Lotito SB \& Fraga CG (2000) Catechins delay lipid oxidation and alpha-tocopherol and beta-carotene depletion following ascorbate depletion in human plasma. Proc Soc Exp Biol Med 225, 32-38.

22. Miura Y, Chiba T, Miura S, Tomita I, Umegaki K, Ikeda M \& Tomita T (2000) Green Tea polyphenols (flavan 3-ols) prevent oxidative modification of low densitylipoproteins - an ex vivo study in humans. J Nutr Biochem 11, 216-222.

23. Miura Y, Chiba T, Tomita I, Koizumi H, Miura S, Umegaki K, Hara Y \& Tomita T (2001) Tea catechins prevent the development of artheroscerosis in apoprotein E-deficent mice. $J$ Nutr 131, 27-32.

24. Joseph JA, Shukitt-Hale B, Denisova N, Bielinski DF, Martin A, McEwen JJ \& Bickford PC (1999) Reversals of age-related declines in neuronal signal transduction, cognitive, and motor behavorial deficits with blueberry, spinach, or strawberry dietary supplementation. J Neurosci 19, 8114-8121.

25. Pan T, Jankovic J \& Le WD (2003) Potential therapeutic properties of green tea polyphenols in Parkinson's disease. Drugs Aging 20, 711-721.

26. Schroeter H, Williams JR, Matin R, Iverson L \& Rice-Evans CA (2000) Phenolic antioxidants attenuate neuronal cell death following uptake of oxidized low-density lipoprotein. Free Radic Biol Med 29, 1222-1233.

27. Kim HK, Kim M, Kim S, Kim M \& Chung JH (2004) Effects of green tea polyphenol on cognitive and acetylcholinesterase activities. Biosci Biotechnol Biochem 68, 1977-1979.

28. Mandel S, Weinreb O, Amit T \& Youdim MBH (2004) Cell signalling pathways in the neuroprotective actions of the green tea polyphenols (-)-epigallocatechin-3-gallate: implications for neurodegenerative diseases. $J$ Neurochem 88, 1555-1569.

29. Benton D, Ruffin MP, Lassel T, Nabb S, Messaoudi M, Vinoy S, Desor D \& Lang V (2003) The delivery rate of dietary carbohydrates affects cognitive performances in both rats and humans. Psychopharmocology 166, 86-90.

30. Messaoudi M, Tricoire A, Lalonde R, Canini F \& Minn A (1996) Effects of MPTP on lever-pressing for light extinction in rats. Eur J Pharmacol 299, 17-20.

31. Messaoudi M, Desor D, Grasmuck V, Joyeux M, Langlois A \& Roman FJ (1999) Behavioral evaluation of visceral pain in a rat model of colonic inflammation. Neuroreport 10, 1137-1141.

32. Morris R (1984) Developments of a water-maze procedure for studying spatial learning in the rat. J Neurosci Methods 11, $47-60$.

33. Armando I, Nowicki S, Aguirre J \& Barontini M (1995) A decreased tubular uptake of dopa results in defective renal dopamine production in aged rats. Am J Physiol 268, 1087-1092.

34. Bisson JF, Guardia-Llorens MA, Hidalgo S, Rozan P \& Messaoudi M (2007) Protective effect of Acticoa powder, a cocoa polyphenolic extract, on prostate carcinogenesis in Wistar-Unilever rats. Eur J Cancer Prev, (In the Press).

35. Siegel S \& Castellan NJ Jr (1988) Nonparametric Statistics for the Behavioural Sciences, 2nd ed. New York: McGraw-Hill.

36. Kaplan EL \& Meier P (1958) Non-parametric estimation from incomplete observations. J Am Stat Assoc 53, 457-481.

37. Lalonde R \& Badescu R (1995) Exploratory drive, frontal lobe function and adipsia in aging. Gerontology 41, 134-144.

38. Rai GS, Shovlin C \& Wesnes KA (1991) A double-blind placebo controlled study of ginkgo biloba extract ('tanakan') in elderly outpatients with mild moderate memory impairment. Curr Med Res Opin 12, 350-355.

39. Kleijnen J \& Knipschild P (1992) Ginkgo biloba for cerebral insufficiency. Br J Clin Pharmacol 34, 352-358.

40. Oyama Y, Fuchs PA, Katayama N \& Noda K (1994) Myricetin and quercetin, the flavonoid constituents of Ginkgo biloba extract, greatly reduce oxidative metabolism in both resting and $\mathrm{Ca}^{2+}$-loaded brain neurons. Brain Res 635, 125-129.

41. Kanowski S, Herrmann WM, Stephan K, Wierich W \& Horr R (1996) Proof of efficacy of the ginkgo biloba special extract EGb 761 in outpatients suffering from mild to moderate primary degenerative dementia of the Alzheimer type or multi-infarct dementia. Pharmacopsychiatry 29, 47-56.

42. Sastre J, Lloret A, Borras C, Pereda G, Garcia-Sala D, DroyLefaix MT, Pallardo FV \& Vita J (2002) Ginkgo biloba extract EGb 761 protects against mitochondrial aging in the brain and in the liver. Cell Mol Biol 48, 685-692.

43. Moriguchi T, Saito H \& Nishiyama N (1997) Anti-aging effect of aged garlic extract in the inbred brain atrophy mouse model. Clin Exp Pharmacol Physiol 24, 235-242.

44. Nishiyama N, Morigushy T \& Saito H (1997) Beneficial effects of aged garlic extract on learning and memory impairment in the senescence-accelerated mouse. Exp Gerontol 32, 149-160.

45. Cao G, Sofic E \& Prior RL (1997) Antioxidant and prooxidant behaviour of flavonoids: structure-activity relationships. Free Radic Biol Med 22, 749-760.

46. Casadesus G, Shukitt-Hale B, Stellwagen HM, Zhu X, Lee HG, Smith MA \& Joseph J (2004) Modulation of hippocampal plasticity and cognitive behaviour by short-term blueberry supplementation in aged rats. Nutr Neurosci 7, 309-316.

47. Lau FC, Shukitt L \& Joseph JA (2005) The beneficial effects of fruits polyphenols on brain aging. Neurobiol Aging 26, Suppl. 1, $128-132$.

48. Matsuoka Y, Kitamura Y, Tsukahara T, Terai K, Tooyama I, Kimura H \& Taniguchi T (1995) Neuroprotective effects of NBQX on hypoxia-induced neuronal damage in rat hippocampus. Neuroreport 6, 2205-2208. 
49. Lee S, Suh S \& Kim S (2000) Protective effects of the green tea polyphenol (-)-epigallocatechin gallate against hippocampal neuronal damage after transient global ischemia in gerbils. Neurosci Lett 287, 191-194.

50. Ishige K, Shubert D \& Sagara Y (2001) Flavonoids protect neuronal cells from oxidative stress by three distinct mechanisms. Free Radic Biol Med 30, 433-446.

51. Crowley TJ, Hoehn MM, Rutledge CO, Stallings MA, Heaton RK, Sundell S \& Stilson D (1978) Dopamine excretion and vulnerability to drug-induced Parkinsonism in schizophrenic patients. Arch Gen Psychiatry 35, 97-104.

52. Hoehn MM, Crowley TJ \& Rutledge CO (1977) The Parkinsonian syndrome and its dopamine correlates. Adv Exp Med Biol 90, 243-254.

53. Pan T, Fei J, Zhou XD, Jankovic J \& Le WD (2003) Effects of green tea polyphenols on dopamine uptake and on MMP + induced dopamine neuron injury. Life Sci 72, 1073-1083.

54. Levites Y, Weinreb O, Maor G, Youdim MB \& Mandel S (2001) Green tea polyphenol (-)-epigallocatechin-3-gallate prevents $N$-methyl-4-phenyl-1,2,3,6-tetrahydropyridine-induced dopaminergic neurodegeneration. J Neurochem 78, 1073-1082.

55. Mercer LD, Kelly BL, Horne MK \& Beart PM (2005) Dietary polyphenols protect dopamine neurons from oxidative insults and apoptosis: investigations in primary rat mesencephalic cultures. Biochem Pharmacol 69, 339-345.

56. Osakabe N, Yamagishi M, Sanbongi C, Natsume M, Takizawa $\mathrm{T}$ \& Osawa $\mathrm{T}$ (1998) The antioxidative substances in cacao liquor. J Nutr Sci Vitaminol 44, 313-321.

57. Cropley VL, Fujita M, Innis RB \& Nathan PJ (2006) Molecular imaging of the dopaminergic system and its association with human cognitive function. Biol Psychiatry 59, 898-907.

58. Lieberman A (2006) Depression in Parkinson's disease - a review. Acta Neurol Scand 113, 1-8.

59. Richard IH (2005) Anxiety disorders in Parkinson's disease. Adv Neurol 96, 42-55.

60. Seutin V (2005) Dopaminergic neurones: much more than dopamine? Br J Pharmacol 146, 167-169.

61. Shook SK, Franz EA, Higginson CI, Wheelock VL \& Sigvardt KA (2005) Dopamine dependency of cognitive switching and response repetition effects in Parkinson's patients. Neuropsychologia 43, 1990-1999.

62. Baba S, Osakabe N, Natsume M, Yasuda A, Takizawa T, Nakamura T \& Terao J (2000) Cocoa powder enhances the level of antioxidative activity in rat plasma. BrJ Nutr 84, 673-680.

63. Rozan P, Hidalgo S, Nejdi A, Bisson JF, Lalonde R \& Messaoudi M (2007) Preventive antioxidant effects of cocoa polyphenolic extract on free radical production and cognitive performances after heat exposure in Wistar rats. J Food Sci 72, S203-S206.
64. Wang JF, Schramm DD, Holt RR, Ensunsa JL, Fraga CG, Schmitz HH \& Keen CL (2000) Dose-response effect from chocolate consumption on plasma epicatechin and oxidative damage. J Nutr 130, Suppl. 85, 2115S-2119S.

65. Lee KW, Kim YJ, Lee HJ \& Lee CY (2003) Cocoa has more phenolic phytochemicals and a higher antioxidant capacity than teas and red wine. J Agric Food Chem 51, 7292-7295.

66. Heiss C, Dejam A, Kleinbongard T, Schewe P, Sies H \& Kelm M (2003) Vascular effects of cocoa rich in flavan-3-ols. JAMA 290, 1030-1031.

67. Sies H, Schewe T, Heiss C \& Kelm M (2005) Cocoa polyphenols and inflammatory mediators. Am J Clin Nutr 81, Suppl. 1, $304 \mathrm{~S}-312 \mathrm{~S}$.

68. Schroeter H, Heiss C, Balzer J, Kleinbongard P, Keen CL, Hollenberg NK, Sies H, Kwik-Uribe C, Schmitz HH \& Kelm M (2006) (-)-Epicatechin mediates beneficial effects of flavanol-rich cocoa on vascular function in humans. Proc Natl Acad Sci U S A 103, 1024-1029.

69. Pearson DA, Schmitz HH, Lazarus SA \& Keen CL (2001) Inhibition of in vitro low-density lipoprotein oxidation by oligomeric procyanidins present in chocolate and cocoas. Methods Enzymol 335, 350-360.

70. Wan Y, Vinson JA, Etherton TD, Proch J, Lazarus S \& KrisEtherton P (2001) Effects of cocoa powder and dark chocolate on LDL oxidative susceptibility and prostaglandin concentrations in humans. Am J Clin Nutr 74, 596-602.

71. Karim M, McCormick K \& Kappagoda CT (2000) Effects of cocoa extracts on endothelium-dependent relaxation. $J$ Nutr 130, Suppl. 85, 2105S-2108S.

72. Mao TK, Powell JJ, Van de Water J, Keen CL, Schmitz HH, Hammerstone JF \& Gershwin ME (2000) The effect of cocoa procyanidins on the transcription and secretion of interleukin-1 $\beta$ in peripheral blood mononuclear cells. Life Sci $\mathbf{6 6}$, $1377-1386$.

73. Sanbongi C, Suzuki N \& Sakane T (1997) Polyphenols in chocolate, which have antioxidant activity, modulate immune functions in humans in vitro. Cell Immunol 177, 129-136.

74. Schramm DD, Wang JF, Holt RR, Ensunsa JL, Gonsalves JL, Lazarus SA, Schmitz HH, German JB \& Keen CL (2001) Chocolate procyanidins decrease the leukotriene-prostacyclin ratio in humans and human aortic endothelial cells. Am J Clin Nutr 73, 36-40.

75. Murphy KJ, Chronopoulos AK, Singh I, Francis MA, Moriarty H, Pike MJ, Turner AH, Mann NJ \& Sinclair AJ (2003) Dietary flavanols and procyanidin oligomers from cocoa (Theobroma cacao) inhibit platelet function. Am J Clin Nutr 77, 466-473.

76. Vita J (2005) Polyphenols and cardiovascular disease: effects on endothelial and platelet function. Am J Clin Nutr 81, Suppl. 1, 292S-297S 